\title{
Relation between pressure and volume in hollow viscera
}

\author{
ANTHONY HOPKINS
}

From the Department of Physiology, Guy's Hospital, and The Institute of Neurology, Queen Square, London

EDITORIAL COMMENT It is suggested that the circumferential tension in the stomach and colon may be calculated as the product of the intravisceral pressure and the square root of the distending volume. Support is found for this hypothesis by suitably transforming previously published data.

Increasing volumes of fluid are accommodated in some hollow viscera without a proportionate increase in pressure. Gianturco (1934) showed that the intragastric pressure does not rise on filling a cat's stomach until unphysiological volumes are reached. As the bladder is filled, the intravesical pressure does not rise linearly with increasing volume but follows a sigmoid curve, the character of which provides useful clinical information as the cystometrogram (Rose, 1927). The response of the colon to filling is similar to that of the bladder (White, Verlot, and Ehrentheil, 1940; Lipkin, Almy, and Bell, 1962).

The Law of Laplace states the relation between the pressure $P$, the radius $R$, and the tension $T$ in a sphere such as, a soap bubble

$$
P=\frac{2 T}{R}
$$

For a cylinder or cone

$$
P=\frac{T}{R}
$$

Various theoretical corrections have been suggested so that this law may be applied to viscera. Allowances are made for the finite thickness of the viscus wall, and for the displacement of overlapping muscle layers during distension (Quigley and Brody, 1950). It is the purpose of this paper to show that the unmodified Law of Laplace is a useful approximation for understanding the response to distension of the stomach and colon.

The stomach can be considered as a cone, the volume of which increases by expansion of the cross-sectional area. As the viscus is fixed at cardia and pylorus, there can be little longitudinal lengthening, a point that is shown by the tracings of Cannon (1898). The colon is a cylinder. The volume of any segment also increases by expansion of the cross-sectional area, without increase in length.

The volume $\mathrm{V}$ of a cone of maximum radius $R$,

and length $h$ is

$$
\frac{\pi}{3} R^{2} h
$$

and for a cylinder

$$
\pi R^{2} h
$$

For either body, as $h$ is constant,

$$
\begin{gathered}
V \alpha R^{2} \\
\text { or } R \alpha \sqrt{V}
\end{gathered}
$$

Substituting $V$ for $R$ in equation (1)

$$
T \alpha P . \sqrt{V}
$$

Thus if the viscus obeys the Law of Laplace, the tension developed circumferentially in the wall is proportional to the product of the internal pressure and the square root of the distending volume. In spite of general appreciation of the Law of Laplace, those who have studied pressure and volume in hollow viscera usually correlate these variables in the original dimensions without deriving this expression. It can, however, be tested using experimental results readily available in the literature.

\section{THE COLON}

The response of the human colon to distension has been investigated by Lipkin et al. (1962). (I am indebted to these authors and the Journal of Clinical Information for allowing me to refer to their extensive data.) In these experiments a balloon was inserted into the sigmoid colon, and distended by water from a constant head of pressure. The intracolic pressure and the flow into the balloon were measured at one-second intervals, and a value $R$, the resistance 
TABLE

CALCULATION OF CIRCUMFERENTIAL TENSION IN COLON EXAMPLE USING DISTENSION 5 OF LIPKIN et al. (1962)

\begin{tabular}{|c|c|c|c|c|c|c|}
\hline 1 & 2 & 3 & 4 & 5 & 6 & 7 \\
\hline$t$ & $p$ & $\Delta V / \Delta$ & $R$ & $V$ & $\sqrt{ } V$ & $P . \sqrt{ } V$ \\
\hline $\begin{array}{l}\text { Time } \\
\text { (sec.) }\end{array}$ & $\begin{array}{l}\text { Intracolic } \\
\text { Pressure } \\
\text { (mm.Hg.) }\end{array}$ & $\begin{array}{l}\text { Rate of Flow } \\
(\mathrm{ml} . / \mathrm{sec} .)\end{array}$ & $\begin{array}{l}\text { Lipkin's } R \\
\text { (units) }\end{array}$ & $\begin{array}{l}\text { Total Volume } \\
(\mathrm{ml} .)\end{array}$ & $\begin{array}{l}\text { Square Root } \\
\text { of Volume }\end{array}$ & $\begin{array}{l}\text { Calculated } \\
\text { Tension (units) }\end{array}$ \\
\hline $\begin{array}{l}1 \\
2 \\
3 \\
4 \\
5 \\
6 \\
7 \\
8 \\
9\end{array}$ & $\begin{array}{l}11 \\
17 \\
20 \\
22 \\
25 \\
26 \\
28 \\
30 \\
32\end{array}$ & $\begin{array}{l}21 \\
29 \\
25 \\
27 \\
22 \\
18 \\
15 \\
10 \\
12\end{array}$ & $\begin{array}{l}0.54 \\
0.60 \\
0.80 \\
0.83 \\
1.14 \\
1.49 \\
1.88 \\
3.00 \\
2.67\end{array}$ & $\begin{array}{r}21 \\
50 \\
75 \\
102 \\
124 \\
142 \\
157 \\
167 \\
179\end{array}$ & $\begin{array}{r}4.6 \\
7.1 \\
8.7 \\
10.1 \\
11.1 \\
11.9 \\
12.5 \\
12.9 \\
13.4\end{array}$ & $\begin{array}{r}51 \\
121 \\
174 \\
222 \\
277 \\
309 \\
350 \\
386 \\
429\end{array}$ \\
\hline
\end{tabular}

of the colon to filling, was calculated from the expression

$$
\frac{\text { Pressure }}{\text { Flow }}=\text { Resistance }(R)
$$

An example of such an experiment is reproduced in columns 1-4 of the Table (distension 5 of Table I of Lipkin et al., 1962).

Values of $R$ for seven distensions at short intervals in one subject are seen in Figure 1. $R$ increases with time, that is to say, with filling, but the increase is neither steady, nor reproducible.

Columns 5-7 of the Table show an example of the circumferential tension calculated in arbitrary units from the expression $T=P . \sqrt{ } V$. The data of

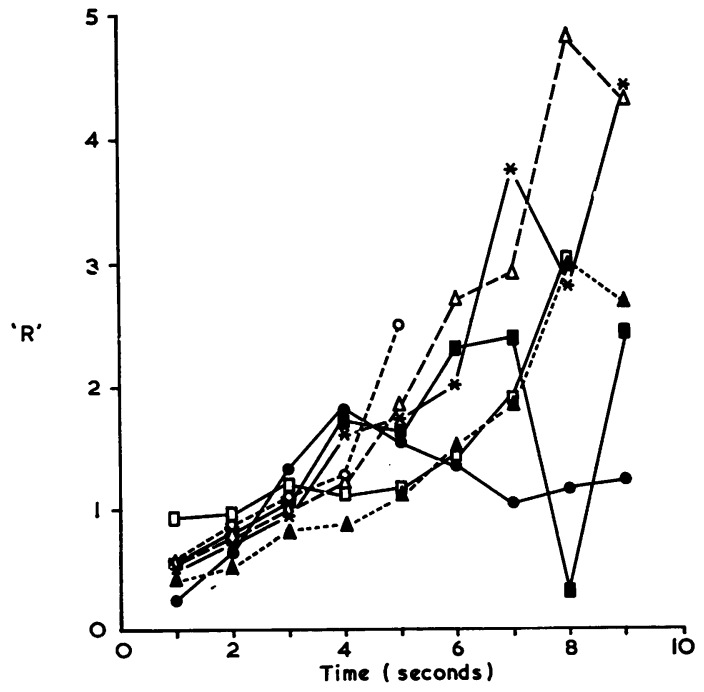

FIG. 1. Ordinate: the calculated $R$ (arbitrary units) of Lipkin et al. (1962), the resistance of the colon to distension. Seven distensions at short intervals in one subject. all seven distensions seen in Fig. 1 have been treated in this way, and plotted against time in Figure 2. Except for the lowest curve the calculated tension increases in a smooth progressive manner, although

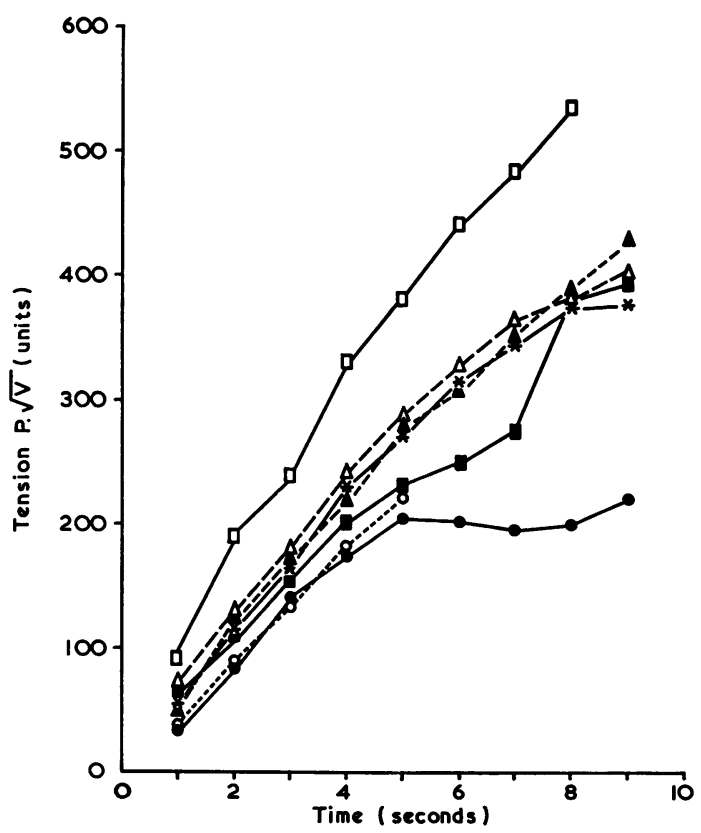

FIG. 2. Ordinate: the calculated circumferential tension P. V (arbitrary unit) from the data of Figure 1.

the rate of flow into the colon varies from second to second, as can be seen in the third column of the Table. As the intracolic pressure rises, the effective filling pressure falls, and the rate of entry of water into the balloon declines. This accounts for the falling off of gradient of the curves in Fig. 2 towards the end of each distension. 


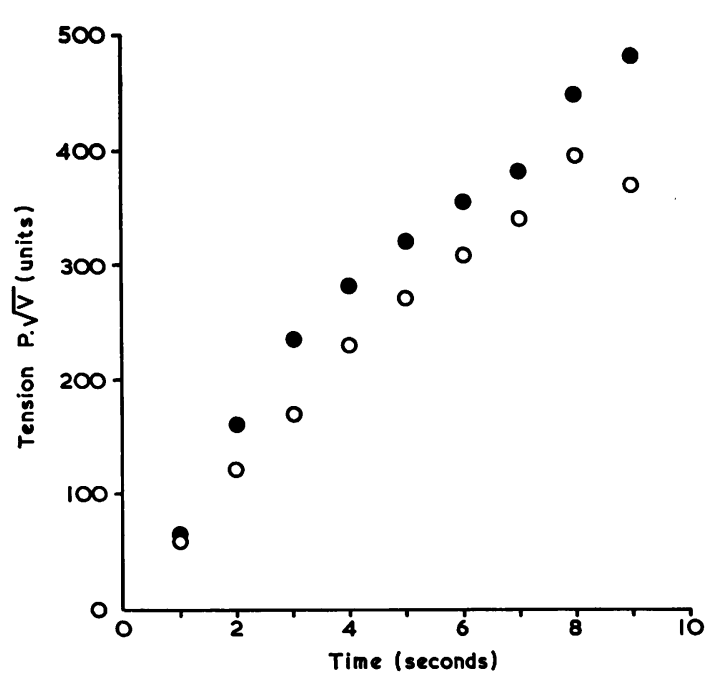

FIG. 3. Ordinate: the calculated circumferential tension $P$. $\sqrt{ } V$ (arbitrary units).

Open circles: mean of seven distensions of Figure 2.

Closed circles: mean of six distensions in the same subject after morphine sulphate $16 \mathrm{mg}$.

Figure 3 shows the effect of $16 \mathrm{mg}$. of morphine sulphate subcutaneously on the calculated colonic tension $(P \cdot \sqrt{ } V)$. The mean calculated tension at each second for the seven distensions of Fig. 2 is shown by the open circles. The closed circles represent the mean calculated tension at each second for six distensions in the same subject after morphine. The calculated tension after morphine is greater at each point but the pattern of increase is similar.

\section{THE STOMACH}

Although this appears to be a reasonable way of calculating circumferential tension in the colon, there is as yet no technique for measuring tenison in vivo. However, Paintal (1954) has measured the frequency of discharge of gastric receptors, which respond to distension of the stomach. He records the rate of discharge of three receptors, examined individually, which were excited by distending balloons in the stomachs of cats. The behaviour of these receptors is recorded in Figs. 9 and 10 of his paper, which he has kindly allowed me to quote. As the pressure in the stomach does not rise until it is unphysiologically distended (Gianturco, 1934), the circumferential tension according to the present hypothesis will be proportional to the square root of the distending volume. The frequency of discharge of these three receptors has therefore been plotted against the square root of the distending volume in Figures 4 and 5. The linear relationship is consistent with the hypothesis. Iggo (1955) showed that gastric contractions induced on a constant volume resulted in an increased frequency of discharge of similar receptors. He suggested that they were tension receptors, in series with the muscle fibres.

Paintal (1954) also showed that many of these receptors were slowly adapting, or even non-adap-
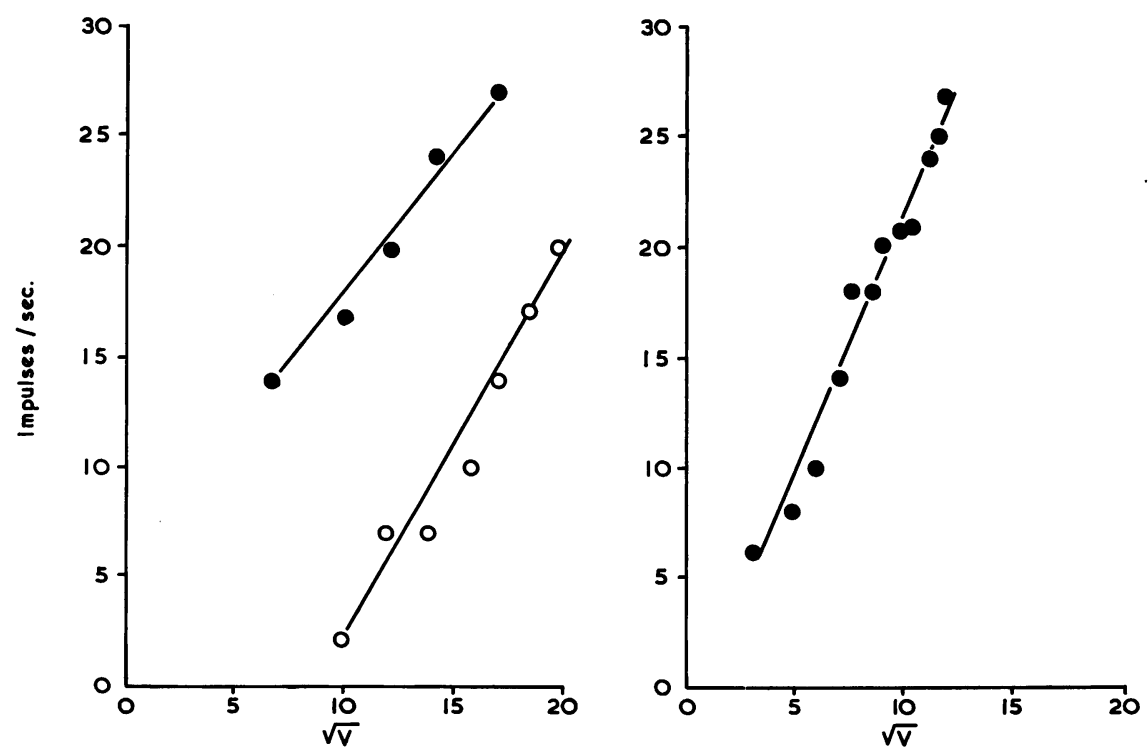

FIGS. 4 and 5.

Ordinates: frequency of discharge of gastric receptors (impulses/ sec.).

Abscissae: square root of the distending volume ( $\mathrm{ml}$.)

Each line represents a different receptor. 
ting. He suggested that the degree of filling of the stomach could thus be signalled.

Cannon (1911) wrote:

'Gastric peristalsis is augmented or weakened, is caused to appear or disappear, as the tension on the contents is increased or decreased.' If gastric propulsion be proportional to gastric tension, as Cannon suggests, then by the square root relationship the rate of emptying should be proportional to the square root of the distending volume. Using data obtained by the serial test meal of Hunt and Spurrell (1951) this proportionality has recently been shown (Hopkins, 1966).

\section{DISCUSSION}

Relatively unpredictable behaviour might be expected from a viscus made of many constituents of differing elastic modulus, controlled by varying levels of humoral and nervous activity. Even isolated organs behave capriciously, depending on the treatment of the tissue after separation from the intact animal (Kesson, 1913). A rubber balloon does not obey the equations predicted for it (Osborne, 1909). However, it seems that the product of the pressure and the square root of the distending volume provides a useful guide to visceral tension.
I am grateful to Dr. Martin Lipkin and Professor A. S. Paintal and to the Journal of Clinical Investigation and the Journal of Physiology for their generosity in allowing me to use their data as examples in support of this hypothesis.

\section{REFERENCES}

Cannon, W. B. (1898). The movement of the stomach studied by means of the Röntgen rays. Amer. J. Physiol., 1, 359-382.

- (1911). The nature of gastric peristalsis. Ibid., 29, 250-266.

Gianturco, C. (1934). Some mechanical factors of gastric physiology. Amer. J. Roentgenol., 31, 735-744.

Hopkins, A. P. (1966). The pattern of gastric emptying. J. Physiol. (Lond.), 182, 144-149.

Hunt, J. N., and Spurrell, W. R. (1951). The pattern of emptying of the human stomach. Ibid., 113, 157-168.

Iggo, A. (1955). Tension receptors in the stomach and in the urinary bladder. Ibid., 128, 593-607.

Kesson, J. E. (1913). The elasticity of the hollow viscera. Quart. J. exp. Physiol., 6, 355-372.

Lipkin, M., Almy, T., and Bell, B. (1962). Pressure-volume characteristics of the human colon. J. clin. Invest., 41, 1831-1839.

Osborne, W. A. (1909). The elasticity of rubber balloons and hollow viscera. Proc. roy. Soc. B., 81, 485-499.

Paintal, A. S. (1954). A study of gastric stretch receptors. Their role in the peripheral mechanism of satiation of hunger and thirst. J. Physiol. (Lond.), 126, 255-270.

Quigley, J. P., and Brody, D. A. (1950). Digestive tract: intralumen pressures: gastro-intestinal propulsion, gastric evacuation, pressure-wall tension relationships. In Medical Physics, edited by O. Glasser, vol. II, pp. 280-292. Year Book Publishers, Chicago.

Rose, D. K. (1927). Determination of bladder pressure with the cystometer. J. Amer. med. Ass., 88, 151-156.

White, J. C., Verlot, M. G., and Ehrentheil, O. (1940). Neurogenic disturbances of the colon and their investigation by the colonmetrogram. Ann. Surg., 112, 1042-1057. 